\title{
The Impacts of Demographic Change on the Functional Economies of the North of England
}

\author{
Philip Rees • Ray Hudson
}

Received: 27 March 2013 / Accepted: 16 April 2013 /

Published online: 3 May 2013

(C) Springer Science+Business Media Dordrecht 2013

\begin{abstract}
In this editorial we pose four questions about the functional economies of northern England in the context of demographic change. How will the northern England population change in the next quarter of a century? What shape will the old of northern England be in and how will we look after them? Are the economies of northern England ready to meet the ageing challenge? Will silver entrepreneurs be able to contribute an economic revival of northern England? These are very important questions, the answers to which will affect the lives of 14 to 15 million people living in a laggard, peripheral European region in the near term future. The answers to these questions are provided by the four papers in this special issue.
\end{abstract}

Keywords Population ageing · Health projections · Implications for pensions · Care worker projections · Dementia projections · Social care policies · Unemployment · Underemployment · Over-education · Older entrepreneurs · Potential for creating businesses

This special issue of ASAP focuses on the theme of demographic change and its impact on the functional economies (city regions) of the North of England, a lagging region compared with the South (particularly, the Greater South East) for many decades. The North now faces the multiple challenges of super-ageing, ethnic composition change, internal redistribution and the downsizing of the public sector of the economy, upon which the region has become dependent. What will be the impacts of these changes on the labour force, on the health, the care needs, the employment prospects and the entrepreneurship of the region? What do the prospects of the North look like when viewed through the prisms

\footnotetext{
P. Rees $(\bowtie)$

School of Geography, University of Leeds, Leeds LS2 9JT, UK

e-mail: p.h.rees@leeds.ac.uk
}

R. Hudson

Department of Geography, Durham University, Science Laboratories, South Road, Durham DH1 3LE, UK 
of local enterprise partnerships rather than regional development agencies? Are there policies that could help or are the prospects for the North just gloomy?

This set of four papers addresses these questions building on new demographic projections of local populations and established economic analysis. The research was carried out collaboratively by a research team from Durham, Leeds, Liverpool, Manchester, Newcastle and York universities, members of the N8 Research Partnership. ${ }^{1}$ The project was funded by a grant to Durham University for the N8 Research Partnership from ONE North East on behalf of the Department of Business, Innovation and Skills, the Department of Communities and Local Government and the Department of Work and Pensions. An Advisory Board from central government and local authority stakeholders provided guidance.

\section{How Will the Northern England Population Change in the Next 25 Years?}

In the first paper, Philip Rees, Chengchao Zuo, Pia Wohland, Carol Jagger, Paul Norman, Peter Boden and Martyna Jasinska extend the information provided by a set of demographic projections to forecast the health and disability status, the labour force size and the number of households in the North of England, its constituent local authorities (LAs) and the new functional groupings of LAs called Local Enterprise Partnerships (LEPs), which "the Government and the private sector increasingly see ... as central to the development of their own local business environment" (Heseltine 2013 , p.34). The paper begins with a review of how the population of northern England arrived at its present size and ageing structure. The process of population ageing had begun with the beginning of fertility decline at the start of the 20th century, but more recently and in the future, ageing, with some recovery in fertility maintained into the future, will be driven by declining mortality. The North has experienced and will experience ageing at a pace close to the national average. Although the North in recent years has lost migrants to the rest of the UK in net terms, these have been more than compensated for by a strong positive balance of immigration from outside the UK.

In order to understand the future implications of ageing it is necessary to use a set of robust population projections. The research team employed the TREND scenario in the ETHPOP $^{2}$ set of projections of the ethnic populations of England's local authorities (Rees et al. 2011a) rather than the ONS (2010) sub-national population projections (SNPP). The differences in the projected local authority populations were not large, as the TREND projections use the same overall assumptions as ONS's national population projections. Under both ETHPOP and SNPP projections, the population of northern England will experience moderate growth with a small variation across LEPs.

The team find that the old age dependency ratio (ODR) in 2036 will be higher (at $47 \%)$ in northern England than in the rest of England (41\%). The highest ODRs (50$59 \%$ ) will be found in the most economically vibrant LEPs (Manchester, Leeds, Sheffield, Cheshire and Warrington), while the lowest ODRs (33-43\%) will be found in less dynamic functional economies or in retirement areas (Lancashire or North

\footnotetext{
${ }^{1}$ The N8 Partnership is a collaboration between eight research-active universities in northern England.

${ }^{2}$ See http://www.ethpop.org/.
} 
Yorkshire). Behind these differences lie contrasts in past population history. In the vibrant cities, the challenge is that the large labour cohorts of the baby boom years will become old in the next 25 years. In the retirement areas, this process is mitigated as previous migrants die off, while in poorer performing functional economies many of the baby boomers migrated away.

The changing age structure of both the national and northern England populations has important implications for pension policy. Projected ODRs in northern England LAs in 2036 revealed that current plans to increase pensionable age to 68 in 2044-2046 are inadequate. The demographic projections suggest the age threshold should increase to 70 by 2036 and to 72 by 2046. These conclusions chime closely with those of the Select Committee on Public Service and Demographic Change (House of Lords 2013, p10), which writes: "The Government were right to raise the state pension age, but they are now adopting a timetable of increases slower than that recommended by the Turner Commission and will have to revisit this with rising healthy life expectancy."

Rees and colleagues also analyse future health trends. Population ageing will have important impacts on the health status of the population of northern England. The rate of increase of the population with limiting long term illness (LLTI) will, at $+25 \%$, be twice that of the total population because the age structure will shift towards the ages at which people experience more illness. Population ageing reflects improvement in survival and longevity but at the expense of more time spent in illness and more people ill, unless illness onset can be delayed by improved health behaviours. Other research (Salomon et al. 2012) finds that healthy life expectancy in most countries of the world, including the $\mathrm{UK}$, is not increasing as quickly as total life expectancy so that expected life with disability is increasing. These conclusions and those of Rees et al. assume constant prevalence of illness by age and sex into the future. The LLTI increases are thus purely a consequence of population ageing. The authors put forward evidence that prevalence rates in the UK have declined over the period since 2000. If this decline were to continue over the next quarter century, it would mitigate the intensifying pressure on the National Health Service which the pure ageing scenario implies.

The paper by Rees and colleagues necessarily presents only summaries of a very rich collection of results, focusing on functional economic areas (the LEPs). Profiles for local authorities are provided in the full research report (Rees et al. 2011b). There is important geographical variation in population change and ageing across northern England, which is discussed in the report and for which the appendices supply detailed information. The authors have assembled the indicators for local authorities and local enterprise partnerships presented here into a local authority spreadsheet with easy access to profiles of key indicators for both LEPs and LAs. This resource is accessible via the net. ${ }^{3}$

\section{What Shape Will the Old of Northern England Be In and How Will We Look After Them?}

In the second paper, Lisa Buckner, Karen Croucher, Gary Fry and Martyna Jasinska address these questions. The demographic changes identified in the first paper have

\footnotetext{
${ }^{3}$ See http://www.n8research.org.uk/research-themes/economic-impacts-of-demographic-change
} 
housing, health and social care implications and present key challenges for public policy and infrastructure planning. These include: a need for more accommodation designed or adapted to be suitable for a diverse population of (much) older people with disabilities or living alone to live relatively independently and an increased need for health monitoring systems, for delivery of healthcare at home and for social care by unpaid carers. These needs will require support by a range of social care services, including home care, assisted living, telecare, personal assistants and other community-based services, plus, for the most frail, residential care. Although these issues are not unique to the North of England, this region has population ageing together with pockets of high levels of deprivation and poverty, contrasting urban and rural areas and communities disproportionally affected by recession. Key issues for an ageing population are the prevalence of disease and of disability status. There is a consensus that population ageing will increase the numbers of people with long-term illness and disability but there is no consensus about whether new treatments which enable people to survive longer with serious illness/disability will reduce or increase costs.

Buckner and colleagues review policies adopted or considered by the last two governments (the Labour administration of 2005-10 and the Conservative-Liberal Democrat administration of 2010-13). The overarching vision is provided in the Coalition Government's White Paper Healthy Lives, Healthy People (Department of Health 2010). This sets out a long-term vision for the future of public health in England, in response to the Marmot Review Team's Fair Society, Healthy Lives (Marmot 2010), which pointed to the need for radical interventions. The White Paper proposed a 'wellness' service and an emphasis on more personalised, preventive services. These were to be achieved by sharing responsibility across the whole spectrum of society with health and social care services and support delivered in a partnership between individuals, communities, the voluntary sector, the NHS and local government. Local government is being empowered to tackle local issues, with central government support, though additional funds will only come through efficiency savings elsewhere.

Policies have been proposed that target people with particular conditions. Aiming High For Disabled Children (Department of Health 2008) was developed to improve the lives of disabled children. Living Well with Dementia (Department of Health 2009a) proposed transforming services for people with dementia to achieve earlier diagnosis and better treatment. Valuing People Now (Department of Health $2009 \mathrm{~b}$ ) aimed to improve the lives of persons with learning disabilities and the lives of carers. No Health without Mental Health (Department of Health 2011) aimed to improve treatment outcomes for people with mental health problems. The policy Lifetime Homes, Lifetime Neighbourhoods (Communities and Local Government 2008) recognised the need to help adapt homes for continued residence by frail elders and proposed enhancement of appropriate services. Buckner and colleagues discuss the challenges of finding or funding enough carers for older people with disability, recognizing the huge contribution made by unpaid relatives and friends. The pressures on social services locally are documented: they are such that the threshold of disability at which care is provided has had to rise steadily.

These national challenges and potential policies play out at regional scale in northern England. To gauge the impact of future ageing on the need for care, Buckner and colleagues extend the methods of the first paper and apply prevalence rates for the most important illnesses and disabilities to the projected populations choosing a 
projection from the ETHPOP set with lower projected population than that used by Rees and colleagues. The prevalence rates are measured nationally from a variety of data from government departments and the 2001 Census and applied to projected local authority populations by age and sex in northern England, with the results mapped by LA and reported in more detail for LEPs. The increases in prospect over the 25 years from 2011 to 2036 are very substantial indeed with nearly two thirds more people aged 65 and over unable to manage one domestic task or self-care facility, with greater increases in the Leeds City Region and Tees Valley conurbation and lower increases in Liverpool City Region and Lancashire. Projected increases in people living with dementia are even greater than these figures. Buckner and colleagues also use the demographic projections with propensities to care derived from the 2001 Census to project the potential number of carers. There is a very small overall increase total number but a decrease when the working ages and those in employment are evaluated. The only favourable trend is in the potential number of carers from Black and Minority Ethnic (BME) groups, where numbers increase by three quarters.

Buckner and colleagues show us that as a society we know what needs to be done and we know, roughly, what the size of the challenge will be in looking after a more aged population over the next quarter of a century. The problem will be to mobilise the resources to match the demand for and supply of care. We cannot be very confident in 2013 that this will be achieved.

\section{Are the Economies of Northern England Ready to Meet the Ageing Challenge?}

Anthony Rafferty, James Rees, Marianne Sensier and Alan Harding assess the recent labour market performance of the functional economic regions of northern England in the third paper. With a glorious past of being a key global driver of the Industrial Revolution, northern England now finds itself a second tier, peripheral region in the European context.

During the economic boom (1996-2006), northern England lagged behind the performance of southern England, driven by the financial service sector focussed in London and high tech industries located in the "Greater South East". Rafferty and colleagues argue that this regional contrast at national scale is repeated within northern England. Selected city regions such as southern Manchester, Leeds, Sheffield and Newcastle were more successful in growing gross value added over the boom decade than peripheral city regions such as Liverpool, Teesside and Hull, though north Manchester had a similar poor performance. Some protection from a poor record in generating private sector and export led jobs was afforded by the expansion of public sector employment. Rafferty and colleagues suggest also that about half the growth in private sector jobs was linked to growth in public spending.

When boom turned to prolonged recession/stagnation from 2007/8, then this structural economic weakness in the northern England employment base was rapidly exposed. Analysis of Job Seekers Allowance (JSA) statistics from 2008 to 2011 across northern England's NUTS3 ${ }^{4}$ regions by the authors show increases in the

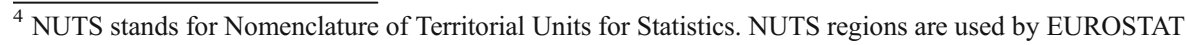
for regional comparisons across Europe
} 
JSA rate ( $\%$ of the economically active population) to be very high, mostly between $50 \%$ and $90 \%$ so that in the most economically challenged northern areas the JSA rate reached 6 to $8 \%$. The internationally comparable unemployment rates based on the Labour Force Survey (LFS) were at least half as high again.

One of the features of the current recession/stagnation is that employment rates have not fallen as unemployment rates have risen. The authors show that this is because workers have switched to involuntary part-time employment. Using the LFS under special licence they computed the percentage of those unemployed who were underemployed. Businesses have been retaining workers though employing them less, hoping to be able to ramp up production swiftly when recovery comes. Labour and unions have accepted this bargain. However, there is some evidence in the models which the authors use to explain part-time employment that women experience such employment downsizing more than men. Involuntary part-time employment tends to be a feature of east coast regions within northern England once composition effects are accounted for, though the reasons for this concentration are not known.

A second symptom of hard times is over-education: the employment of highly educated workers in jobs below their skill levels (i.e. over-qualification). Between $20 \%$ and $30 \%$ (depending on NUTS2 region) of holders of Level 4/5 qualifications are working in 'non-graduate' occupations in northern England. A model that controls for composition of the labour force indicates all northern regions experience this over-education in comparison with Inner London. On graduation from northern universities graduates compete for professional and managerial jobs in the nation's capital and its golden halo. Analysis by the authors show that the under-employment may be an early recession phenomenon while over-education manifests later in times of economic difficulty when young workers accept temporary low skill jobs while continuing to look for better paid employment.

In a final piece of analysis Rafferty and colleagues show how damaging public expenditure cuts have been to local authorities in northern England compared with southern LAs. Of the 16 worst affected LAs in England only three (Hackney, Newham and Tower Hamlets) are not in northern England. Of the 15 least affected LAs only one, Cheshire East, is located in northern England. Although the analysis applies LA spending plus NHS spending on social care, the same redistribution is likely for NHS expenditure by Clinical Commissioning Group beyond 2014, consequent on a new formula for resource allocation developed under the Conservative-Liberal Democrat Coalition which dropped the part of the formula which compensated for health inequalities (Campbell 2012).

The economic experience of northern England over the past two decades, as documented by Rafferty and colleagues, does not bode well for the future, even if the UK economy does manage to recover to 2007 output levels before the end of the current Parliament (probably in 2015). The Heseltine review points that the way forward to re-empower business and local government is to be innovative and enterprising in investment and economic development strategies. The Government response (HMT and BIS 2013), endorsed by George Osborne, the Chancellor of the Exchequer and by Vince Cable, Secretary of State for Business, Innovation and Science, was positive but the next two years will show whether the necessary leadership will be delivered. 


\section{Will Silver Entrepreneurs Be Able to Contribute an Economic Revival of Northern England?}

Tom Cannon and Kasia Kurowska try to answer this question in the final paper. The paper by Rees and colleagues established that population ageing necessitated retaining more older workers in employment to continue earning and contributing taxes and to reduce the retired population who cease economic activity and draw public benefits. The paper by Rafferty and colleagues established that the economy of northern England was in poor shape. Cannon and Kurowska surveyed a set of older workers or recent retirees who were considering becoming entrepreneurs. The set was built up through an LA network of contacts, explicit LA programmes to help older entrepreneurs get started and personal contacts. The survey was supplemented by some in-depth interviews. The authors indicate that official statistics report that northern England had a low stock of businesses in relation to the economically active population and a low rate of business start-ups compared with other regions in England. As Rafferty and colleagues noted the region is also more dependent on public sector employment. Will northern England produce the 'silver' entrepreneurs to correct this poor performance?

Cannon and Kurowska see plenty of potential for the 50 to 74 age group to found successful businesses: they are large in number, over 4 million with considerable assets. They find positive attitudes to self-employment and business creation across the population. The result is increasing business formation in this group. Seniors do have good networks and some confidence from their previous careers which stand them in good stead in setting up their own businesses. However, there are countervailing factors at work: a relatively poor environment of similar businesses within the region with which the potential silver entrepreneur could collaborate and few large firms interested in nurturing an ecosystem of suppliers and innovators who are older entrepreneurs. Also potential silver entrepreneurs are rather risk averse, being unwilling to risk their sole residence or pension pot in a speculative venture. There is not much evidence that older business people have a market advantage when servicing the senior market. The example set by B and Q Do-It-Yourself chain in deliberately hiring older labour able to communicate and advise an ageing DIY clientele seems not to have been replicated. Cannon and Kurowska point to the need for training programmes designed to skill older workers for business and for support from financial institutions for such starting businesses.

\section{Concluding Remarks}

These four papers paint a rather gloomy picture of prospects "up North", compared with the positive spin of the Government's response to the Heseltine Review. The authors have not shrunk from telling it as they see it. Before successful treatment must come accurate diagnosis. Population ageing is a long-term process which gives plenty of warning of impending effects. Policy on pensions has been shifted through these kinds of diagnosis. However, a region experiencing population ageing and simultaneously a poor economic performance needs to rise to the challenge and seeing an older population as part of the solution is a start. 
Acknowledgements The research reported in these papers was funded by a grant from ONE North East on behalf of the Department of Business, Innovation and Skills, the Department of Communities and Local Government and the Department of Work and Pensions to the Northern Eight Research Universities Partnership. The project was guided by an Advisory Board of central government and local stakeholders. The papers also benefitted from prior research funded by a variety of organizations including ESRC. Extensive use was made of data produced by UK government departments which is sourced and acknowledged in each paper. All authors are grateful for the suggestions and comments made by a set of engaged referees from a variety of social science disciplines.

\section{References}

Campbell, D. (2012). NHS spending plan hits poorer areas, critics claim. The Guardian, Tuesday 22 May. Online at: http://www.guardian.co.uk/society/2012/may/22/nhs-spending-plan-hits-poorer-areas.

Communities and Local Government. (2008). Lifetime homes, lifetime neighbourhoods: a national strategy for housing in an ageing society. London: Department for Communities and Local Government, Department of Health, Department for Works and Pensions. Online at: http://www.communities.gov.uk/ publications/housing/lifetimehomesneighbourhoods.

Department of Health. (2008). Aiming high for disabled children. London: The Stationery Office. Online at: http://webarchive.nationalarchives.gov.uk/20100612050234/http:/www.dcsf.gov.uk/everychildmatters/ healthandwellbeing/ahdc/coreoffer/coreofferandni/.

Department of Health. (2009a). Living well with dementia: a national dementia strategy. London: The Stationery Office. Online at: http://www.dh.gov.uk/en/Publicationsandstatistics/Publications/ PublicationsPolicyAndGuidance/DH_094058.

Department of Health. (2009b). Valuing people now. London: The Stationery Office. Online at: http:// www.valuingpeoplenow.dh.gov.uk/sites/dhvpnweb.rroom.net/files/webfm/Valuing\%20People\% 20Now\%20Landing\%20Page/Valuing\%20People\%20Now\%20Strategy\%20.pdf.

Department of Health. (2010). Healthy lives, healthy people: our strategy for public health in England. London: The Stationery Office. CM7985. Online at: http://www.official-documents.gov.uk/document/ cm79/7985/7985.pdf.

Department of Health. (2011). No Health with Mental Health: a cross-government mental health outcomes strategy for people of all ages. London: The Stationery Office. Online at: http:/www.iapt.nhs.uk/silo/ files/no-health-without-mental-health.pdf.

Heseltine, M. (2013). No stone unturned in pursuit of growth. A report by the Rt Hon the Lord Heseltine of Thenford CH, Department of Business, Innovation and Science. Online at: http://www.bis.gov.uk/ assets/biscore/corporate/docs/n/12-1213-no-stone-unturned-in-pursuit-of-growth.

HMT and BIS (2013). Government's response to the Heseltine review. Cm8587. Her Majesty's Treasury and Department of Business, Innovations and Skills. Online at: http://www.official-documents.gov.uk/.

House of Lords (2013). Ready for ageing? Report, Select Committee on Public Service and Demographic Change, Report of Session 2012-13. HL Paper 140. London: The Stationery Office. Online at: http:// www.parliament.uk/business/committees/committees-a-z/lords-select/public-services-committee/ publications/.

Marmot, M. (2010). Fair society, healthy lives. London: The Marmot Review. Online at: http:// www.marmotreview.org/AssetLibrary/pdfs/Reports/FairSocietyHealthyLives.pdf.

ONS (2010). 2008-based subnational population projections for England. Statistical Bulletin. Online at: http://www.ons.gov.uk/ons/rel/snpp/sub-national-population-projections/2008-based-projections/ index.html.

Rees, P., Wohland, P., Norman, P., \& Boden, P. (2011a). A local analysis of ethnic group population trends and projections for the UK. Journal of Population Research, 28(2-3), 149-184.

Rees, P., Zuo, C., Wohland, P., Jagger, C., Norman, P., Boden, P., et al. (2011b). Modelling demographic change: projecting future population, health, labour force and households in Northern England. Final Report, Strand 1 for N8 Research Partnership, The impacts of demographic change in the functional economies of the North of England. Online at: http://www.n8research.org.uk/research-themes/economicimpacts-of-demographic-change.

Salomon, J. A., Wang, H., Freeman, M. K., Vos, T., Flaxman, A. D., Lopez, A. D., et al. (2012). Healthy life expectancy for 187 countries, 1990-2010: a systematic analysis for the Global Burden Disease Study 2010. Lancet, 380, 2144-2162. 